\title{
A prototype for IoT based Rice Field Irrigation System
}

\author{
Muhamad Fuat Asnawi \\ Universitas Sains Al-Quran \\ Wonosobo, Indonesia \\ fuatasnawi@unsiq.ac.id
}

\author{
Fitri Syukriasari \\ Universitas Sains Al-Quran \\ Wonosobo, Indonesia \\ fitrisyukriasari@gmail.com
}

\begin{abstract}
-irrigation is a very important factor and as a support that will affect agricultural products. The increase in managing agriculture is also very much needed in the era that has entered the current industrial era 4.0. Water becomes a basic resource to support agricultural activities, if there is no water, the activity will not work. In general, Rice field irrigation runs using conventional methods which are carried out from sources such as rivers. The lack of supervision of the irrigation system has made the performance of the irrigation system not optimal. With this, an irrigation canal regulator is needed and along with these problems, a prototype for IoT based Rice Field Irrigation System is made. This prototype has several functions, namely as a regulator of opening and closing irrigation canals by referring to the condition of water level and soil moisture, as well as monitoring the temperature and humidity conditions of the air around the rice fields. This prototype uses a telegram bot as an internet-ofthings media control. A prototype for IoT based Rice Field Irrigation System as a tool to open the paddy irrigation canal using a modular IoT-based algorithm with a Telegram bot media that has been successfully designed and built
\end{abstract}

Keywords - Internet of Things; Rice Field Irrigation; telegram bot

\section{INTRODUCTION}

Indonesia is known as an agricultural country because most of Indonesia's population has jobs in agriculture. As an agrarian country, Indonesia is blessed with abundant natural resources which are located in the tropics which have high rainfall so that many types of plants can live and grow well. So Indonesia is often expressed with the phrase "gemah ripah loh jinawi", which has extraordinary meaning and meaning that is peaceful, prosperous and very fertile land [1].

In terms of farming, water resources play an important role in the period of plant growth. Especially in growing rice in paddy fields which also require a fairly good irrigation distribution channel. Maintenance and regulation of rice field irrigation still uses conventional methods. Most irrigation systems in Indonesia still use manual systems, namely systems where opening and closing irrigation channels to rice fields are still traditional.

Farmers must always come to the rice fields to monitor and open the irrigation canal, so also other farmers, must alternate according to the time to drain the water through irrigation canals used together.

Technological developments in the present day have a profound effect on innovation and the creation of sophisticated tools, such as tools that can work automatically and in a controlled manner. Many produce solutions that can solve human problems. Problems that arise from human limitations or from other factors, now little by little can be overcome. One solution that can solve human problems is by using a computer-based control system. Various tools with computer-based control systems are expected to help and alleviate human work and become a solution for every human problem.

In a previous study applied an IoT model in the Rice Field Irrigation control system by Sugiono with the research title "Kontrol Jarak Jauh Sistem Irigasi Sawah Berbasis Internet Of Things". This study uses several tools such as the HC-SR04 ultrasonic sensor to retrieve air altitude data, the Wemos D1 ESP8266 microcontroller as the center of control and uses an android application connected to the node controller using the Key API from web hosting[2]. 
In this case the solution to be achieved is to use a microcontroller with the ESP8266 platform. Replacing control from manual to automatic, one of which is the use of Internet of Things (IoT) -based technology. This technology can be a solution in saving human energy and time because it allows monitoring to be carried out remotely via a computer or smartphone. This tool aims to improve the effectiveness of the work of farmers and through this tool it is also expected to facilitate the work of farmers, help farmers to stream water to the fields from long distances and close distances through social media telegram bots on the condition that the network is online. The strength of this research with previous research is the addition of several sensors so that the irrigation system runs better and uses telegram bots as a control system.

The rice field irrigation control system uses telegram bot media by utilizing the features of Telegram. Have access to open and close irrigation water gates and monitor conditions around the rice fields. The system will automatically open and close according to the high water level and soil moisture on irrigation, it can also be controlled according to the wishes of farmers. Monitoring can be accessed remotely starting from sluice conditions, temperature, soil moisture and air and high water. To minimize program errors, the system applies a modular algorithm. Modular is used on complex problems, so the first step is to identify the main task, after which it is divided into more detailed tasks or in sub-programs. Because each sub-program represents their respective tasks.

With this background, the researcher solves the problem by making a tool that can realize the technological response to the work mentioned above with the title "A prototype for IoT based Rice Field Irrigation System”.

\section{THEORETICAL BASIC}

\section{A. Internet Of Things}

Internet of Thing or IoT is an architecture consisting of hardware, software systems, Web API, protocols that together create a smooth environment where smart embedded devices can be connected to the internet such as sensor data can be accessed and the control system can be moved through the internet.

Devices can be connected to the internet using various methods such as Ethernet, WIFI, Bluetooth, and so on. Devices may also not be technically technically straight on the internet, but are grouped in clusters (for example sensor networks) and connected to the base station (connected to the internet) [3].

\section{B. Wemos microcontroller}

The microcontroller is a microprocessor system in which there are CPUs, ROMs, RAM, I / O, clocks and other equipment that are interconnected and well organized by the manufacturer and packaged in one chip that is ready to use [4]. Microcontroller is a single computer chip that can be used to control the system, besides that its shape is small and the price is cheap so it can be embedded in various household appliances, offices, industries or robots [5].

Wemos microcontroller is a development microcontroller based on the ESP8266 microcontroller module. The Wemos microcontroller is made as a solution to the high cost of a wireless system.

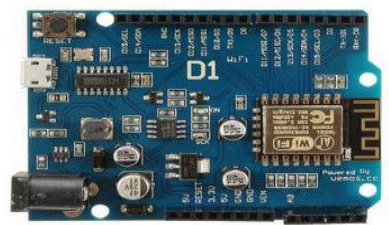

Fig. 1. Wemos Microcontroller D

\section{Soil moisture sensor}

The soil moisture sensor is able to measure the water content in the soil, with 2 probes at the end of the sensor. This sensor can be inserted into the ground to measure the moisture contained in the soil.

Electrical conductance on the ground can be measured easily using two separate metal conductors in the soil, except that the soil contains a lot of salt, which changes the conductivity of the water and can disrupt the measurement. In a type YL-69 sensor moisture set there is a module in which there is an LM393 IC which functions for a lace offset process that is lower than $5 \mathrm{mV}$, which is very stable and precise. The sensitivity of detection can be adjusted by rotating the potentiometer installed in the processor 28 module. For precision detection using a microcontroller or Arduino, it can use analog output (the connection with the ADC or analog input pins on the microcontroller) which will provide moisture values on a scale of $0 \mathrm{~V}$ (relative to GND) to VCC (power supply voltage). This module can use a power supply between 3.3 volts to 5 volts so that it is flexible to be used on a variety of microcontrollers. Sensor output voltage between 0 to $4.2 \mathrm{~V}$ with a current of $35 \mathrm{~mA}$. There are three connector pins on the sensor, namely analog output, ground, and VCC. [6] 


\section{Water Level Sensor}

Water level sensor is a tool used to detect the presence of water / water droplets at a low cost and easy to use. There is a series of parallel conductors on the sensor that can detect depth / height or detect water droplets. This sensor output is an analog signal that will be read by the MCU, such as Arduino, to be processed to determine the water depth. This sensor is perfect for outdoor equipment such as weather stations, which require a sensor to measure the intensity of rain outdoors. Plus this sensor is not expensive so it can save on the cost of making tools. [7].

\section{SYSTEM DESIGN CONSIDERATIONS}

\section{A. How the system works}

The workflow of the Internet of Things prototype controls the rice irrigation system using Telegram bot media. Using the ESP8266 Wemos D1 board microcontroller so that the tool can be controlled remotely with the concept of the Internet of Things.

The prototype can multiply and also monitor rice field irrigation canals. Channel opening and closing controls depend on the condition of the existing sensor values, in this case using 2 types of sensors, namely water level sensors and soil moisture sensors. The function of the water level sensor is to monitor whether the water level of the paddy field is in accordance with the desired, which is between 2$5 \mathrm{~cm}$ during the growing period of the rice plant. While the soil moisture sensor serves to monitor dry or wet conditions of the rice fields. With a Telegram bot the user can control and monitor the conditions of humidity and air temperature, open the lid of the irrigation canal, conditions of soil moisture and also the condition of the water level.

\section{B. Block Diagram}

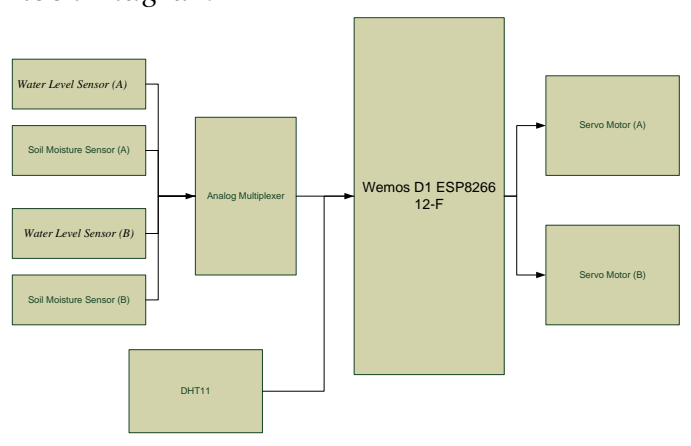

Fig. 2. Block Diagram
From the block diagram in figure 2 the author describes the information and functions between the blocks of the block diagram as follows:

\section{1) Soil Moisture Sensor}

Enabled as input to the microcontroller to detect soil moisture, dry or wet or even moist.

2) Water Level Sensor

Enabled as input to the microcontroller to detect water level

3) DHTI1

Enabled as input to the microcontroller to monitor temperature and humidity

4) Servo Motor $S G 90$

Functioned as a prototype of a rice field irrigation actuator canal.

5) Wemos D1 ESP8266

As a microcontroller that is used as a control center. Blocked this program is embedded in the microcontroller to control the output by adjusting from the input.

6) Arrows

Is a process flow path from the sensor input to the microcontroller then the output will move or turn on according to the input conditions.

\section{Mechanical Design}

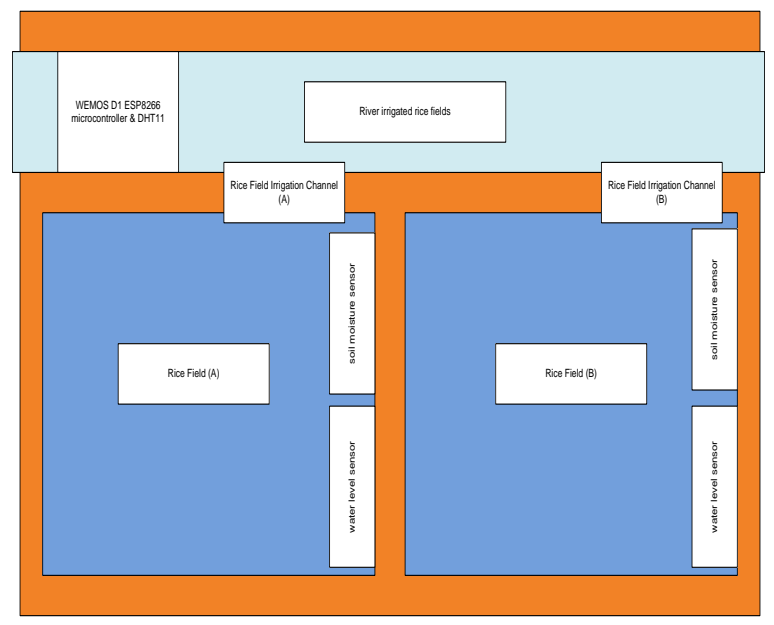

Fig. 3. Mechanical Design

Picture 3 is as follows:

- Design in the form of 2 rice fields and 1 irrigation river.

- Water level sensors and soil moisture sensors are installed in each paddy field 
- DHT11 sensors and microcontrollers are placed in areas near irrigation river flow

- Each rice field has its own irrigation canal

The mechanical tools used are from acrylic materials that are designed and arranged specifically for the purposes of this tool system research. This tool is designed in such a way that all electronic components can be installed and work properly.

\section{Overall Scheme}

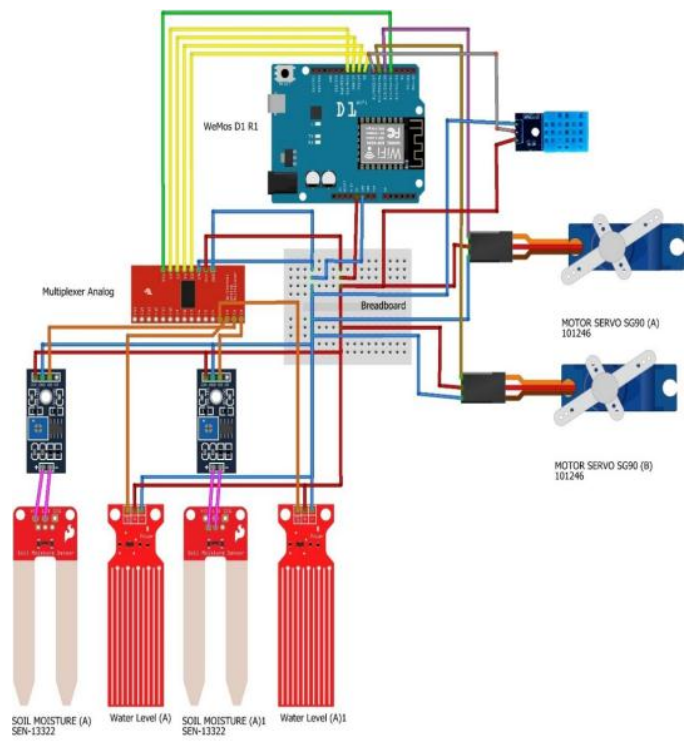

Fig. 4. Overal Scheme

I/O Pin Configuration on Wemos:

TABLE I. I/O PIN CONFIGURATION ON WEMOS

\begin{tabular}{|l|l|l|}
\hline I/O Pin & Function & \multicolumn{1}{c|}{ Explanation } \\
\hline VCC & Input & Positive supply voltage (5V) \\
\hline GND & Input & Negative supply voltage \\
\hline D11 & Input & Analog Multiplexer Input \\
\hline D10 & Input & Analog Multiplexer Input \\
\hline D9 & Input & Analog Multiplexer Input \\
\hline D8 & Input & Analog Multiplexer Input \\
\hline D7 & Input & $\begin{array}{l}\text { Temperature and Humidity } \\
\text { Sensors (DHT11) }\end{array}$ \\
\hline D6 & Output & SG90 Servo Motor \\
\hline D5 & Output & SG90 Servo Motor \\
\hline D4 & Input & Analog Multiplexer Control Input \\
\hline
\end{tabular}

\section{E. Telegram Bot System}

In the telegram bot, there are two methods, namely:

\section{Long Polling Connections}

2. Webhooks Connections

In this study the authors used the Long Polling Connections method. Long-Polling, as the name implies, in theory this method will open a connection that is ready to accept requests as long as the bot server is run, for this method we do not need an SSL or Domain name, because it can be run via an internet-connected laptop or computer, but weakness using this method lies in the speed of reading or replying to incoming requests, because there will be a pause of several seconds to read and respond to requests sent by the bot client to the bot server.

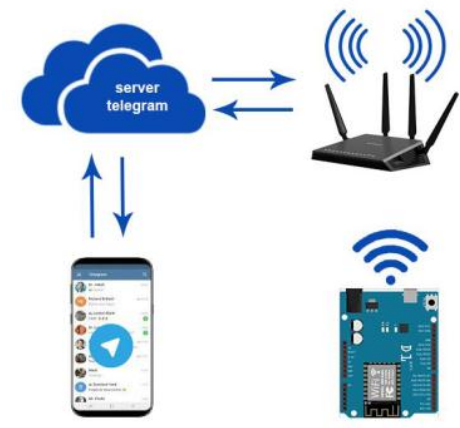

Fig. 5. Telegram Bot Scheme

The first step in making a telegram bot is to register a bot account first. By using the @botfather service from Telegram. There are several commands provided by @botfather. Then select the command / newbot to create a new bot and fill in as ordered. The bot registration aims to get a bot token that is used to get tokens which will be used for programming on the Wemos D1 ESP8266 microcontroller.

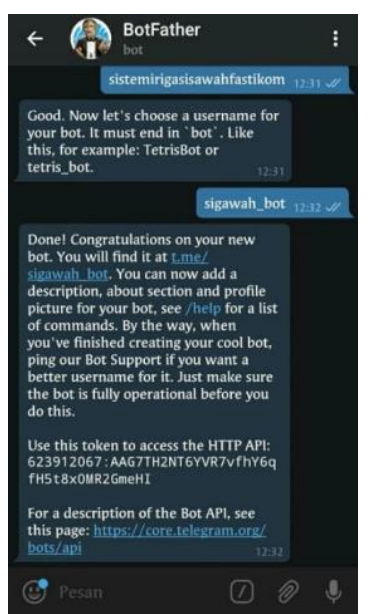

Fig. 6. Register for the telegram bot at @ botfather 


\section{RESULT}

\section{A. Hardware}

The hardware that has been successfully made in this study is A prototype for IoT based Rice Field Irrigation System or it can be called "SIGAWAH".

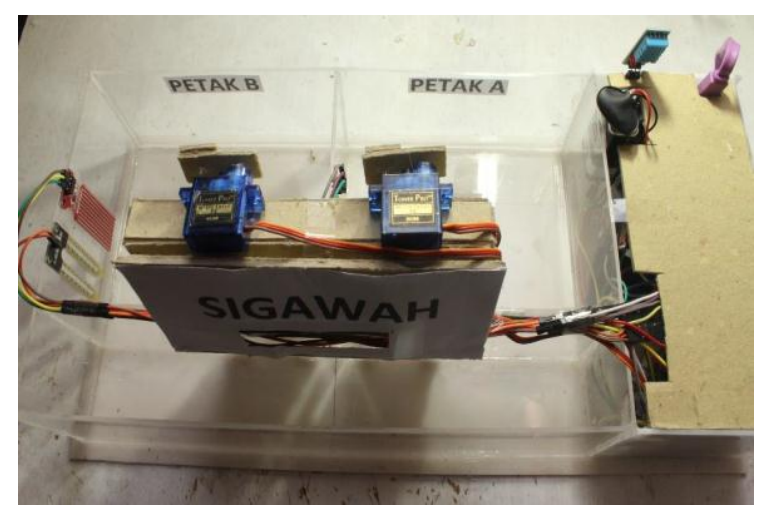

Fig. 7. Sigawah

Sigawah consists of a series of temperature and humidity, irrigation canal circuit, LCD circuit, 16 Channel analog MUX sensor circuit and a series of soil moisture and water levels. The explanation of the results of making hardware devices is as follows:

\section{1) Air Temperature and Humidity Schema}

In this circuit using a DHT11 sensor where the ADC data on the sensor is connected to pin D2 on Wemos. With the required voltage of $3.3 \mathrm{~V}$.

\section{2) Irrigation Channel Schema}

In this circuit using an actuator, the SG90 servo where the servo pin is connected to 14 and 12 PWM pins on Wemos. With the required voltage of $4.8 \mathrm{~V}$ on each servo. Servo work will alternate because the voltage of the wemos is only $5 \mathrm{~V}$.

\section{3) LCD Schema}

In this LCD circuit I2C is used as serial communication to Wemos microcontroller, it also saves cabling. With the required voltage of $5 \mathrm{~V}$. Special additional power for LCDs uses a $9 \mathrm{~V}$ battery.

\section{4) 16 Channel Analog MUX Sensor Schema}

This analog Mux sensor circuit is used as a connecting line for analog sensors where Wemos only has 1 analog pin. The voltage needed is $2 \mathrm{~V}$.

\section{5) Soil Moisture And Water Level Schema}

The soil moisture level and water level are connected using the 16 Channel Analog multiplexer. The voltage required for soil moisture and also the water level sensor is 5 $\mathrm{V}$ for the maximum.

\section{B. Software}

Software used for A prototype for IoT based Rice Field Irrigation System the program is written in $\mathrm{C}$ language using Arduino software. Whereas for the online control system using Telegram social media which is utilizing a bot which is a feature of the Telegram itself.

\section{1) Arduino}

Using the Arduino IDE as software to program an IoT-based Wemos microcontroller on the basis of the $\mathrm{C}$ programming language.

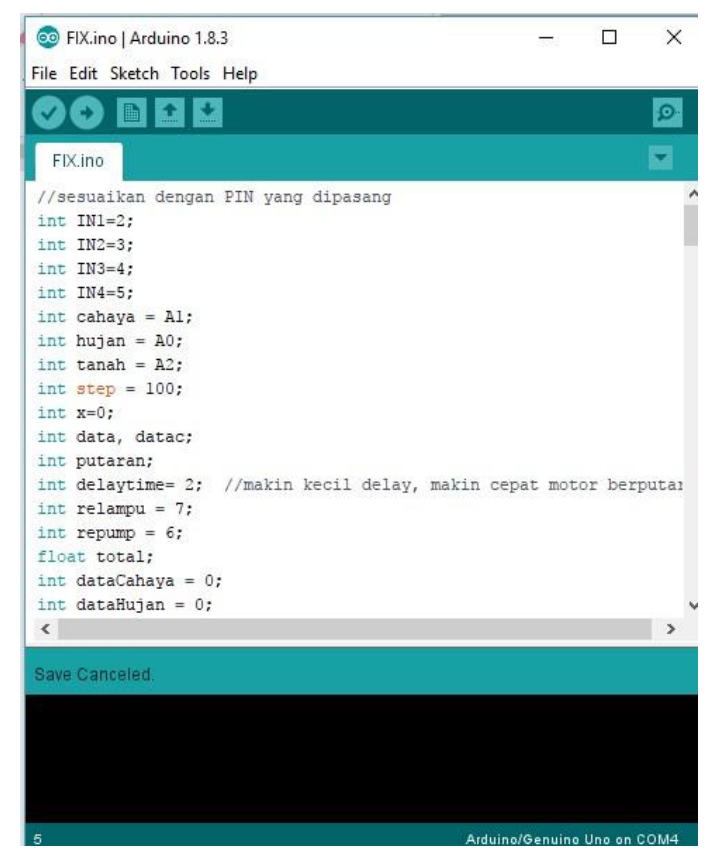

\section{2) Bot Telegram}

Fig. 8. Arduino IDE

Utilizing the features that are in the Telegram is a bot that can be integrated with a microcontroller. The most important thing when an IoT system can run is that there is network connectivity, which is the same as used in this study. Access can only be made to users who have already set up with a specific telegram account ID. On this Sigawah account can be found with the name @ @igawah_bot, for other users only can see it can't access the existing menu. 


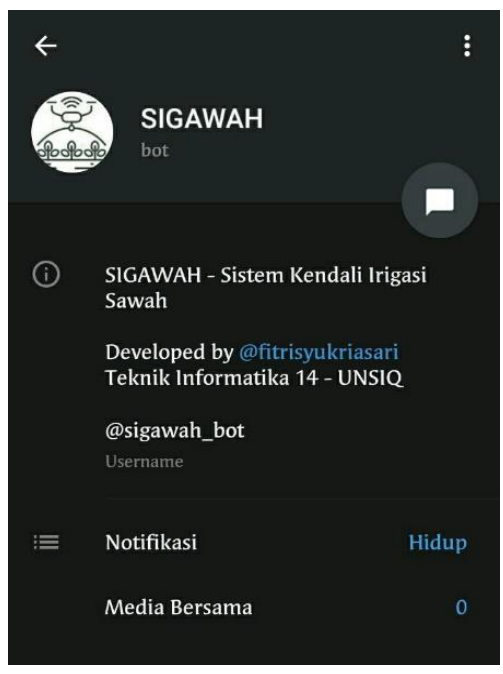

Fig. 9. Sigawah account on Telegram bots

\section{CONClusion}

From the results of the research that has been done, the conclusions are as follows:

1. The use of the long polling connections method has the disadvantage of the average delay time on the telegram command bot can reach 30 seconds.

2. The system can only be accessed with 1 bot with 1 token number and can only be accessed and ordered by 1 user.

3. A prototype for IoT based Rice Field Irrigation System as a tool to open the paddy irrigation canal using a modular IoT-based algorithm with a Telegram bot media that has been successfully designed and built.

\section{REFERENCES}

[1] N. Burhan, "Penggunaan Ungkapan Jawa Dalam Kumpulan Puisi Tirta Kamandanu Karya Linus Suryadi”, UNY LITERA, the International Journal of Linguistics, Literature, and Their Teaching, October 2014.

[2] Sugiono, Indriyani, T., and Ruswiansari, M. "Kontrol Jarak Jauh Sistem Irigasi Sawah Berbasis Internet Of Things", INTEGER: Journal of Information Technology, September 2017.

[3] M. Priyono, T. S, D.A Nugraha, N. Sari, N. Karima, and W Asrori, "Implementasi IoT (Internet of Things) dalam pembelajaran di Universitas Kanjuruhan Malang", SMARTICS Journal, October 2015.

[4] Ardi. Winoto, "Mikrokontroler AVR Atmega8/16/32/8535 dan Pemrogramannya Dengan Bahasa $\mathrm{C}$ pada winAVR. Informatika, Bandung. 2008.

[5] Ibrahim. Dogan. "Microcontroller Based Applied Digital Control", Cyprus : John Willey and Sons, Ltd. 2006.

[6] Prasetyo, Eri Nur. "Prototype Penyiram Tanaman Persemaian Dengan Sensor Kelembaban Tanah Berbasis Arduino”. Universitas Muhammadiyah Surakarta. 2015.
[7] Adhitya, MVN, Hafidudin, Sarwoko. "Design And Realization Automatic Of Taps And Water Tank Filling With Ultrasonic Sensor And Liquid Water Level Using AtMega 328" e-Proceeding of Engineering. Telkom University. 2015 